\title{
EDITORIAL
}

\section{The Complexity of and Opportunity for Screening in Primary Care}

\author{
Kurt C. Stange, $M D, P b D$, Editor \\ Ann Fam Med 2009;7:2-3. DOI: 10.1370/afm.960
}

$\mathrm{T}$ his issue features articles on the early detection of disease and risk factors.

Four of these articles ${ }^{1-4}$ and an editorial ${ }^{5}$ showcase colorectal cancer screening. Three of these studies evaluate the role of primary care in colorectal cancer early detection. A study using nationally representative data ${ }^{1}$ shows that colorectal cancer screening rates are associated with having a personal clinician, as well as with social factors. In contrast, Jimbo and colleagues $^{2}$ find that primary care physician decisions are a major factor in patients not undergoing complete evaluation for a positive fecal occult blood screening test. To further complicate the picture of the role of primary care physicians in colorectal cancer screening, Wilkins conducts a meta-analysis of 12 studies of colonoscopy by primary care physicians, finding quality parameters similar to those in studies of specialists. ${ }^{4}$

The fourth colorectal cancer screening study, featured as this issue's Annals Journal Club selection, is a clinical trial of a pragmatic intervention that links fecal occult blood testing to influenza immunization clinics. The dramatic effect shows that, when properly configured, complementary services can represent competing opportunities ${ }^{6}$ rather than competing demands. ${ }^{7}$

Several other studies in this issue address screening for other conditions. Jeppesen and colleagues find complementary value in several different brief screens for health literacy. ${ }^{8}$ Gjerdingen et $\mathrm{al}^{9}$ find that the optimal strategy for identifying women with postpartum depression may be a 2-stage screening procedure that involves using a 2 -item initial screen, followed by a 9 -item instrument for those whose screening test was positive. Rhodes et $\mathrm{al}_{1}{ }^{10}$ screening for intimate partner violence among men seen in an urban emergency department, find the highest rate of mental health symptoms occur among men who disclose both victimization and perpetration. This finding shows that the simplistic label of victim or perpetrator masks a more complex problem. A clinical policy guideline based on a systematic review ${ }^{11}$ finds strong evidence for screen- ing patients for depression after myocardial infarction and moderate to strong evidence for treatment.

A population-based study of children with asthma finds greater prescribing variability in younger children. $^{12}$

Patient requests for specific new prescriptions are found in $3.5 \%$ of patient visits to clinicians in a practice-based research network. ${ }^{13}$ Although physicians reported that the requested medication was not their first choice for treatment, in $62 \%$ of these instances, the medication was prescribed $53 \%$ of the times it was requested. Despite this finding, clinicians reported a negative impact from these requests, stimulated by direct-to-consumer advertising, in only $10 \%$ of visits.

An essay by Buetow uses the art concept of negative space to help us see patients and situations (and sometimes ourselves) in relief, separated from preconception and focused on the moment. ${ }^{14}$

Please share your insights on these articles and your experience with the important topics they bring up by joining the Annals online discussion at http://www. AnnFamMed.org.

To read or post commentaries in response to this article, see it online at http:I/www.annfammed.org/cgi/content/full/7/1/2.

\section{References}

1. Cardarelli R, Thomas JE. Having a personal health care provider and receipt of colorectal cancer testing. Ann Fam Med. 2009;7(1):5-10.

2. Jimbo M, Myers RE, Meyer B, et al. Reasons patients with a positive fecal occult blood test do not undergo complete diagnostic evaluation. Ann Fam Med. 2009;7(1):11-16.

3. Potter MB, Phengrasamy L, Hudes ES, McPhee SJ, Walsh JME. Offering annual fecal occult blood tests during flu shot clinics increases colorectal cancer screening rates. Ann Fam Med. 2009;7(1):17-23.

4. Wilkins T, LeClair B, Smolkin M, et al. Screening colonoscopies by primary care physicians: a meta-analysis. Ann Fam Med. 2009;7(1):56-62.

5. Berg AO. The aftermath of efficacy. Ann Fam Med. 2009;7(1):3-4.

6. Stange KC, Jaén CR, Flocke SA, Miller WL, Crabtree BF, Zyzanski SJ. The value of a family physician. J Fam Pract. 1998;46(5):363-368. 
7. Jaén $C R$, Stange KC, Nutting PA. Competing demands of primary care: a model for the delivery of clinical preventive services. J Fam Pract. 1994;38(2):166-171.

8. Jeppesen KM, Coyle JD, Miser WF. Screening questions to predict limited health literacy: a cross-sectional study of patients with diabetes mellitus. Ann Fam Med. 2009;7(1):24-31.

9. Gjerdingen D, Crow S, McGovern P, Miner M, Center B. Postpartum depression screening at well-child visits: validity of a 2-question screen and the PHQ-9. Ann Fam Med. 2009;7(1):63-70.

10. Rhodes KV, Houry D, Cerulli C, Straus H, Kaslow NJ, McNutt L. Intimate partner violence and comorbid mental health conditions among urban male patients. Ann Fam Med. 2009;7(1):47-55.
11. Post-Myocardial Infection Depression Clinical Practice Guideline Panel. AAFP Guideline for the detection and management of postmyocardial infarction depression. Ann Fam Med. 2009;7(1):71-79.

12. Zuidgeest MGP, van Dijk L, Spreeuwenberg P, et al. What drives prescribing asthma medication to children? A multilevel populationbased study. Ann Fam Med. 2009;7(1):32-40.

13. Parnes B, Smith PC, Gilroy C, et al. Lack of impact of direct-to-consumer advertising on the physician-patient encounter in primary care: a SNOCAP report. Ann Fam Med. 2009;7(1):41-46.

14. Buetow SA. Something in nothing: negative space in the clinicianpatient relationship. Ann Fam Med. 2009;7(1):80-83.

\title{
EDITORIAL
}

\section{The Aftermath of Efficacy}

\author{
Alfred O. Berg, MD, MPH \\ Department of Family Medicine, University of Washington, Seattle, Washington \\ Ann Fam Med 2009;7:3-4. DOI: 10.1370/afm.959
}

A s a member of the US Preventive Services Task Force for 12 years and its chair for 5, I have given countless presentations on Task Force recommendations. During questions and comments, clinicians often voice frustration and even hostility to the recommendations because the Task Force does not advise on exactly what should happen next. My response is that, indeed, the science is the easy part and that effective implementation is hard, particularly in a health care environment that discourages system innovation. Although the process of sifting through the medical literature to determine the quality of evidence that supports (or fails to support) a preventive intervention is time consuming, costly, and, at times, tedious, it is not particularly complicated. If the Task Force has set up the analytic framework correctly, identified the key questions, and carefully followed protocol in completing the evidence review, the conclusions usually follow easily. Screening for colorectal cancer is a good exam-

Conflict of interest: none reported

\section{CORRESPONDING AUTHOR}

Alfred O. Berg, MD, MPH

Department of Family Medicine

University of Washington

Box 354696

Seattle, WA 98195

aberg@u.washington.edu ple of where the science showing efficacy of screening is fairly straightforward, but where the paths to effective implementation are not. In its updated recommendation released in October, 2008, ${ }^{1}$ the Task Force has judged that screening works, but then what?

Four articles in the current issue of the Annals of Family Medicine address "then what" in different ways. Potter and colleagues show that offering fecal occult blood kits to patients during flu shot clinics increased screening from $57 \%$ to $84 \%{ }^{2}$ Using data from the Behavioral Risk Factors Surveillance System, Cardarelli and Thomas show that having a personal health care provider is associated with a 3-times higher likelihood of screening. ${ }^{3}$ Jimbo and colleagues examined reasons that positive fecal occult blood tests were not followed up, finding that such decisions were at variance from established guidelines or could not be determined in nearly one-half. ${ }^{4}$ Finally, Wilkins' group conducted a quantitative meta-analysis of the literature on the outcomes of screening colonoscopies performed by primary care physicians, showing that quality, safety, and efficacy are similar to indicators proposed by specialty professional groups. ${ }^{5}$ These new articles are high-quality work, showing imagination and skill on the part of the investigators. My comments briefly address the audiences of physicians, patients, and policy makers.

Physicians eager to implement prevention in practice have long recognized the importance of an established relationship and of using every opportu- 